\title{
Kinetic Control of Protonation in Electrospray Ionization
}

\author{
J. Richard Joyce, Don S. Richards
}

Pfizer Global Research and Development, Analytical Development, Ramsgate Road, Sandwich, Kent CT13 9NJ, UK

\begin{abstract}
The site of protonation in a molecule can greatly affect the fragments observed in product ion MS/MS spectra. In electrospray positive ionization mass spectra, protonation usually occurs predominantly on the most basic site on the molecule to produce the thermodynamically favored protonated species. However, the literature is unclear whether liquid phase or gas phase thermodynamics has the greater influence. This paper describes the protonation and fragmentation behavior of crizotinib and two of its impurities. Crizotinib has two possible protonation sites, a pyridine nitrogen and a secondary amine, piperidine nitrogen; the former is the favored site in the gas phase and the latter the more favored site in the liquid phase. The impurities contain alkyl substitution on the piperidine nitrogen, producing tertiary amine species. Literature precedence suggests that in the liquid phase, the piperidine nitrogen is still the most basic site but, in the gas phase, the pyridine nitrogen and the piperidine nitrogen have very similar basicities. Fragmentation data for the three molecules suggest that the secondary and tertiary amines protonate preferentially and almost exclusively on different sites. We propose that the secondary amine protonates on the piperidine nitrogen (influenced by solution thermodynamics) and the two tertiary amine structures protonate on the pyridine nitrogen because of steric hindrance at the most basic site of the molecule, allowing kinetic control of the protonation process.
\end{abstract}

Key words: MS, MS/MS, Protonation site, Kinetic effect, Steric hindrance

\section{Introduction}

E lectrospray is a widely used ionization technique in mass spectrometric investigations of active pharmaceutical ingredients (API) and related products. Ionization, which takes place at atmospheric pressure, occurs directly from the liquid phase [1] and, therefore, is eminently suited for use in conjunction with high pressure liquid chromatography (HPLC). In electrospray positive (ES+) mode, the ionization process often results in protonation of the intact molecule $\left([\mathrm{M}+\mathrm{H}]^{+}\right.$adduct ions), particularly when there is a basic site in the molecule, such as an amine function. Where no such site is present, ionization can still occur through the production of alternative adduct ions, such as $\left[\mathrm{M}+\mathrm{NH}_{4}\right]^{+}$or $[\mathrm{M}+\mathrm{Na}]^{+}$ions in addition to or instead of

Correspondence to: J. Richard Joyce; e-mail: richard.joyce@pfizer.com
$[\mathrm{M}+\mathrm{H}]^{+}$ions. Where more than one basic site is present in the molecule, as in the example of crizotinib, it is possible that protonation can occur at different sites or at several sites simultaneously to give multiply charged ions.

The site of protonation in a molecule is important in understanding the fragments observed in full scan mass spectrometry (MS) experiments and in MS/MS product ion experiments, and ultimately in the ability to accurately interpret MS and MS/MS data from unknown compounds in order to elucidate their structures. This is generally thought to be influenced predominantly by thermodynamic considerations, i.e. by the relative basicity, or $\mathrm{p} K a$ value, of the possible protonation sites. Once protonation has occurred, it is possible that intramolecular proton transfers can take place via collisional activation to produce thermodynamically less favored species, which may undergo rapid fragmentation [2-4]. It is also possible that the most basic 
site in a molecule might differ in the gas phase from that in the liquid phase [5-7] and that proton transfer may occur during the evaporation and desolvation process. Tian and Kass [8] have also shown that the site of protonation in paminobenzoic acid changes from N-protonation when analyzed from acetonitrile/water solution to O-protonation in methanol/water solution because of this effect.

Kinetic control of protonation site, in which a thermodynamically less favored site reacts preferentially because of steric hindrance at the favored site, has been reported $[2,3,9$, 10] for gas phase ionization techniques such as chemical ionization (CI). Similar kinetic control has not been reported for liquid phase ionization, and might not be expected because of the greater opportunity for equilibrium to be established in the liquid phase, particularly in the time scale of a HPLC analysis. It is well established that acids, such as formic acid, can be used as mobile phase modifiers in electrospray negative ionization, and several authors [11-14] have noted that compounds can be analyzed in electrospray positive ionization using high $\mathrm{pH}$ mobile phases with no loss of sensitivity compared with low $\mathrm{pH}$ mobile phases. This suggests that the degree of ionization (protonation) of analyte in solution may not be a critical factor in the electrospray ionization process.

ES+ HPLC-MS analysis of crizotinib and impurities indicates that the API molecule itself protonates, as expected, on the liquid phase most basic nitrogen and MS and MS/MS spectra can be rationalized from this proposition. However, two impurities, which were identified as having substituents attached to the most basic site, were found to give significantly different MS and MS/MS spectra. This is believed to be caused by predominant protonation of a second, less favored, basic nitrogen because of steric hindrance at the favored site.

\section{Experimental}

\section{Mass Spectrometry}

A Bruker (Conventry, UK) maXis mass spectrometer was used operating in the ES+ ionization mode using standard operating parameters. Accurate mass calibration was achieved by introducing sodium formate solution $(10 \mathrm{mM}$, aqueous) into the ionization source at the beginning and end of the HPLC run. MS/MS collision induced dissociation (CID) spectra were produced with Argon collision gas at collision energies ranging between 20 and $25 \mathrm{eV}$. An isolation width of $6 \mathrm{Da}$ was used to make use of isotope distributions in the MS/MS spectra to verify formula assignment.

Data processing was performed using Bruker DataAnalysis software, including the chemical formula assignment software, SmartFormula (SF) [15-19] and SmartFormula3D (SF3D) [20, 21]. The former uses isotope pattern comparison, as well as mass measurement to produce a 'sigma fit' with $\mathrm{m} \sigma$ values of less than 20 indicating an excellent match with theoretical. Acceptable values of $m \sigma$ can be higher for low intensity ions or for ions that have distorted isotope distributions because of interfering signals. In addition, SF3D makes use of fragment formula assignment in MS/ MS spectra to further improve the accuracy of chemical formula assignment of the $[\mathrm{M}+\mathrm{H}]^{+}$ion by the recognition that the formula of any fragment must be a subset of the formula of the $[\mathrm{M}+\mathrm{H}]^{+}$ion.

\section{Chromatography}

Analytical HPLC conditions consisted of a Sunfire (Water Ltd., Elstree, UK) C18 column $(150 \times 4.6 \mathrm{~mm}, 3.5 \mu)$ operated at $25^{\circ} \mathrm{C}$. Gradient LC conditions were established with mobile phases of $10 \mathrm{mM}$ ammonium formate adjusted to $\mathrm{pH} 2.5$ with trifluoroacetic acid (A) and acetonitrile (B) Initial conditions were $90 \%$ A (held for $2 \mathrm{~min}$ ) followed by a gradient to $30 \% \mathrm{~A}$ at $40 \mathrm{~min}$. The flow rate was $0.5 \mathrm{~mL} / \mathrm{min}$ and $10 \mu \mathrm{L}$ of a $1.0 \mathrm{mg} / \mathrm{mL}$ solution of crizotinib in methanol/water (1/1) was analyzed. These conditions allowed the separation of two impurities from crizotinib.

\section{Results and Discussion}

\section{Crizotinib}

The structure of crizotinib, $\mathbf{1}$, is shown below, along with predicted $\mathrm{p} K a$ values [22] for the four most basic sites. The $\mathrm{p} K a$ values suggest that at $\mathrm{pH} 2.5$ both the piperidine nitrogen and the pyridine nitrogen will be protonated in aqueous media, although at this elution time the mobile phase contains approximately $54 \%$ acetonitrile and therefore the true $\mathrm{pH}$ is likely to be higher. We would predict from a solution thermodynamic view point that the piperidine nitrogen would protonate most readily and that the mass spectrum may show some contribution from doubly charged species caused by additional protonation of the pyridine nitrogen.

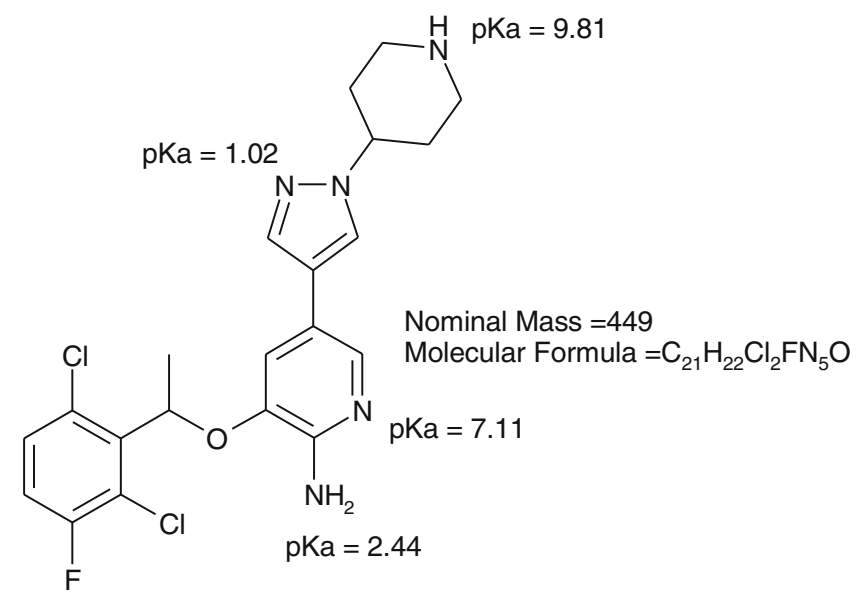




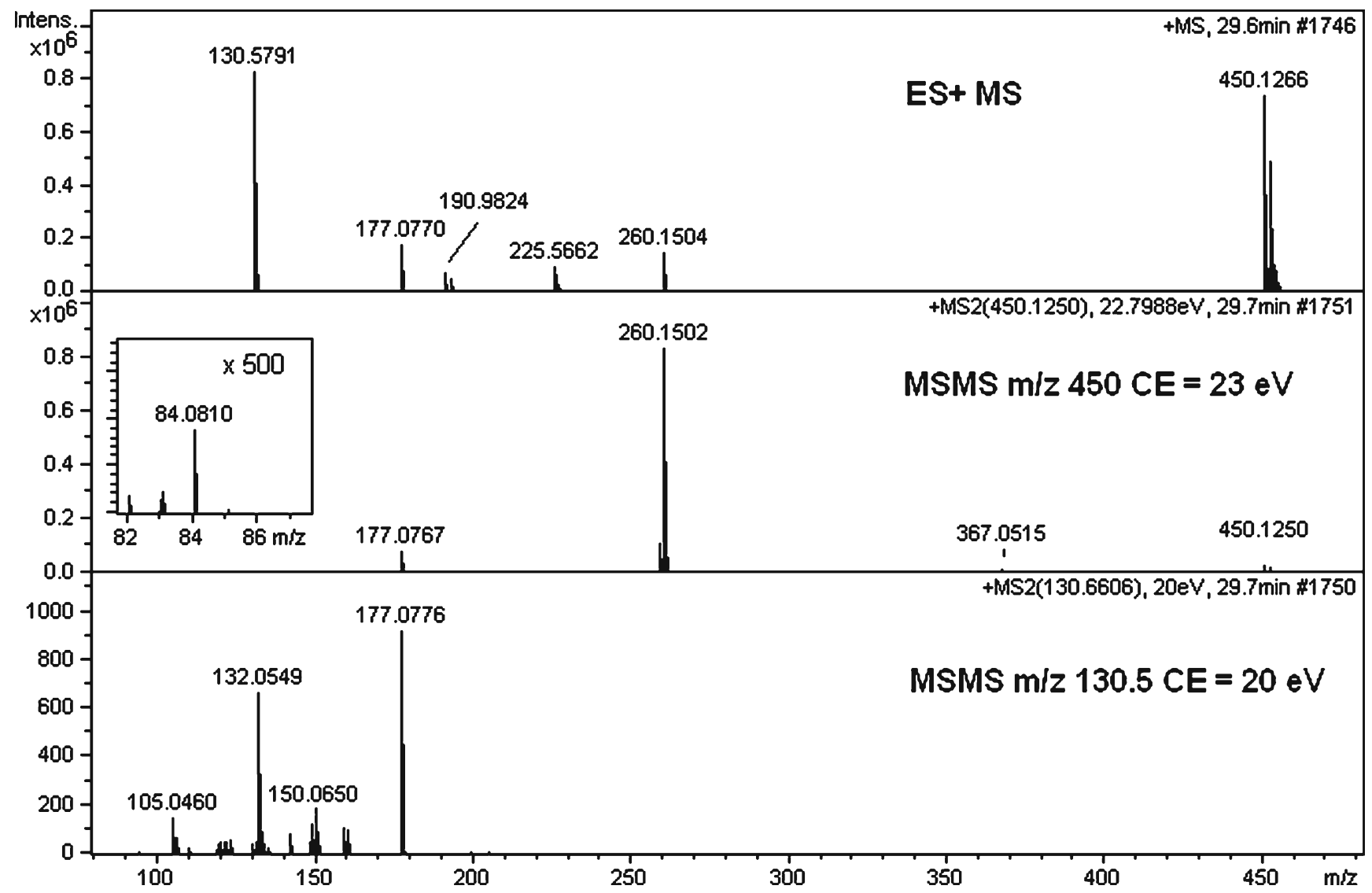

Figure 1. ES+ MS and MS/MS data for crizotinib. Top: Full Scan MS. Middle: MS/MS product ion data for $\mathrm{m} / \mathrm{z} 450$ (collision energy $23 \mathrm{eV}$ ). Bottom: MS/MS product ion data for $\mathrm{m} / \mathrm{z} 130.5$ (collision energy $20 \mathrm{eV}$ )

The ES+ MS and MS/MS spectra of crizotinib are shown in Figure 1. A dichlorinated $[\mathrm{M}+\mathrm{H}]^{+}$ion is observed at $\mathrm{m} / \mathrm{z} 450.1266$, consistent with $\mathrm{C}_{21} \mathrm{H}_{23} \mathrm{Cl}_{2} \mathrm{FN}_{5} \mathrm{O}$ (calculated $\mathrm{m} / \mathrm{z}$ 450.1258, $\mathrm{m} \sigma=8.7$ ). A doubly charged $[\mathrm{M}+2 \mathrm{H}]^{2+}$ ion is also observed at $\mathrm{m} / \mathrm{z} 225.6$. A significant fragment ion is observed at $m / z 260.1504\left(\mathrm{C}_{13} \mathrm{H}_{18} \mathrm{~N}_{5} \mathrm{O}\right.$, calculated $\mathrm{m} / \mathrm{z} 260.1506, \mathrm{~m} \sigma=1.4)$ and its doubly charged equivalent $\left(\mathrm{C}_{13} \mathrm{H}_{19} \mathrm{~N}_{5} \mathrm{O}^{2+}\right.$, calculated $\mathrm{m} / z$ 130.5789, $\mathrm{m} \sigma=$ 5.7) is also seen as an intense fragment at $\mathrm{m} / z$ 130.5791. The ES+ MS spectrum also shows a dichlorinated fragment at $\mathrm{m} / \mathrm{z} 190.9824\left(\mathrm{C}_{8} \mathrm{H}_{6} \mathrm{Cl}_{2} \mathrm{~F}\right.$, calculated $\mathrm{m} / \mathrm{z}$ 190.9825) and a fragment at $\mathrm{m} / z 177.0770\left(\mathrm{C}_{8} \mathrm{H}_{9} \mathrm{~N}_{4} \mathrm{O}\right.$, calculated $\mathrm{m} / \mathrm{z}$ 177.0771). In addition, a dichlorinated $\mathrm{m} / \mathrm{z} 367 \mathrm{frag}$ ment is observed in the MS/MS spectrum of $\mathrm{m} / \mathrm{z} 450$, a very low intensity fragment is observed at $m / z 84\left(\mathrm{C}_{5} \mathrm{H}_{10} \mathrm{~N}\right)$ and $m / z 177$ further fragments to $m / z 160,159,150$, and 132. These data are fully consistent with the structure and predicted protonation behavior of crizotinib, as shown in Scheme 1.
Impurity $A, \mathrm{~m} / \mathrm{z} 506$

ES+ MS and MS/MS data for Impurity A are shown in Figure 2. A dichlorinated $[\mathrm{M}+\mathrm{H}]^{+}$ion is observed at $\mathrm{m} / \mathrm{z}$ 506.1889, consistent with $\mathrm{C}_{25} \mathrm{H}_{31} \mathrm{Cl}_{2} \mathrm{FN}_{5} \mathrm{O}$ (calculated $\mathrm{m} / \mathrm{z}$ $506.1884, \mathrm{mo}=13.8)$. A doubly charged $[\mathrm{M}+2 \mathrm{H}]^{2+}$ ion is also observed at $\mathrm{m} / \mathrm{z}$ 253.6. The MS and MS/MS data are tabulated in Table 1 to indicate chemical formulae assignments of the ions, as verified by SF and SF3D. The formula is $\mathrm{C}_{4} \mathrm{H}_{8}$ higher than that of crizotinib and the MS/MS spectrum of $\mathrm{m} / \mathrm{z} 506$, shows a loss of $\mathrm{C}_{4} \mathrm{H}_{8}$ to give $\mathrm{m} / \mathrm{z}$ 450.1254 (see above). The $\mathrm{m} / \mathrm{z} 367$ fragment is again observed and the presence of a low intensity $\mathrm{m} / \mathrm{z} 140$ fragment $\left(\mathrm{C}_{9} \mathrm{H}_{18} \mathrm{~N}\right)$ locates the extra butyl group on the piperidine ring nitrogen.

The structure of Impurity A $(\mathrm{m} / \mathrm{z} 506)$ is assigned as the N-t-butyl analogue, 2, after consideration of the synthetic route. The piperidine nitrogen is now even more basic because of the positive inductive effect of the 


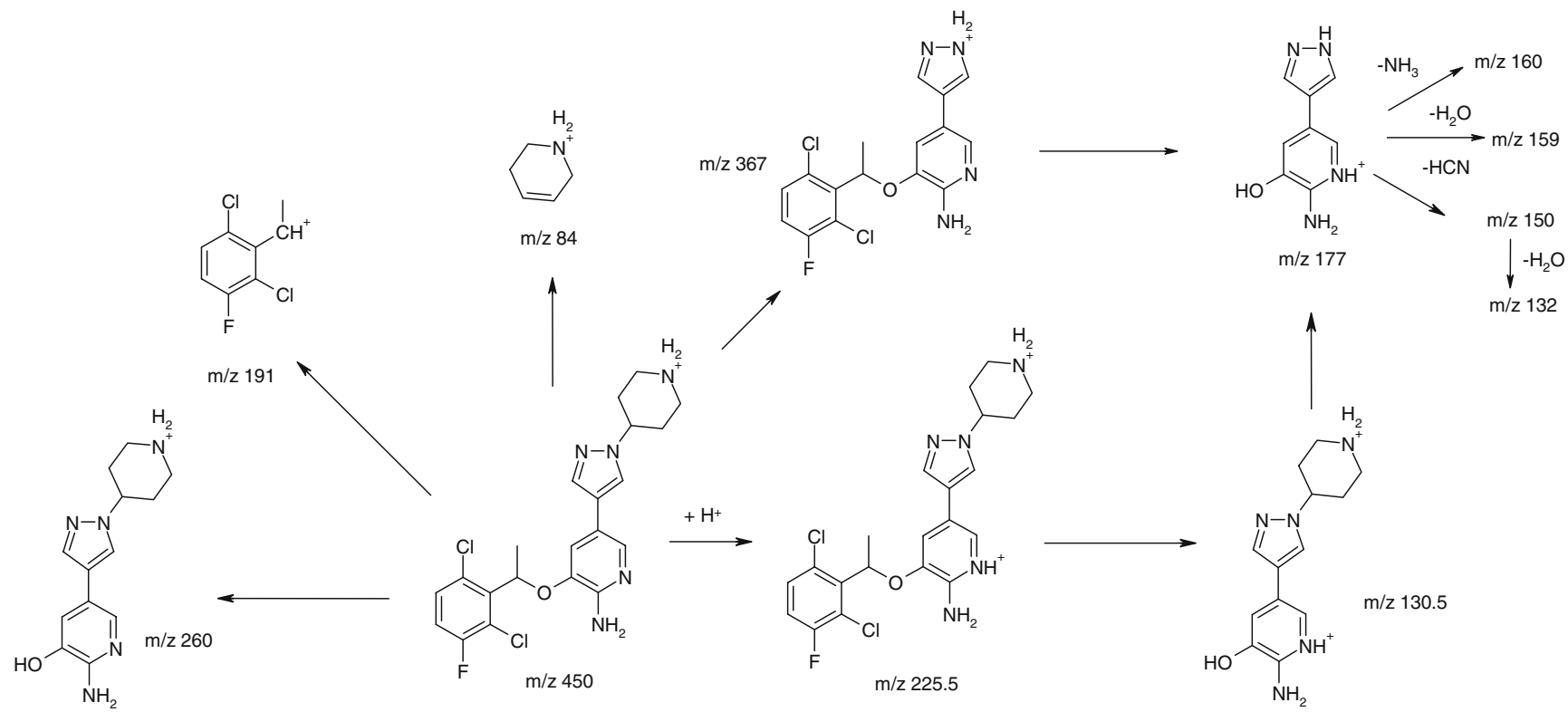

Scheme 1. Crizotinib-MS and CID MS/MS fragmentation

t-butyl group and, like crizotinib, the piperidine nitrogen would be expected to protonate in preference to the pyridine nitrogen, based on solution thermodynamic considerations.

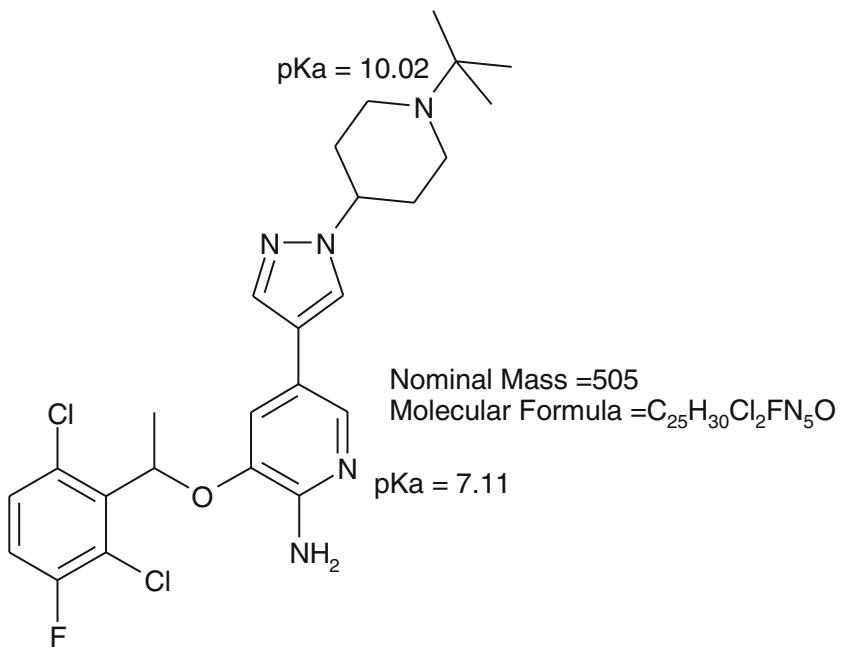

2

This would be expected to lead to the compound ionizing and fragmenting in a similar way to crizotinib. In fact, fragmentation is quite different. In the MS spectrum, doubly charged ions are present, but not to the same extent as in crizotinib. Cleavage at the phenolic oxygen results in an odd-electron ion $(\mathrm{m} / \mathrm{z} 315)$, rather than $\mathrm{m} / \mathrm{z} 316$, which would be the equivalent of the $\mathrm{m} / \mathrm{z} 260$ fragment observed in the data for crizotinib. This ion further loses $\mathrm{C}_{4} \mathrm{H}_{8}$ to give another odd-electron ion at $\mathrm{m} / \mathrm{z}$ 259. The $m / z 177$ fragment is observed (see above) as well as the odd-electron equivalent ion, $m / z$ 176. These differences must be due to a difference in the predominant site of protonation of the $[\mathrm{M}+\mathrm{H}]^{+}$ion in the two molecules. If protonation occurs on the pyridine nitrogen, the fragmentation of Impurity A $(\mathrm{m} / \mathrm{z} 506)$ can be rationalized, as in Scheme 2.

\section{Impurity $B, m / z 522$}

ES+ MS and MS/MS data for Impurity B are shown in Figure 3. A dichlorinated $[\mathrm{M}+\mathrm{H}]^{+}$ion is observed at $\mathrm{m} / \mathrm{z}$ 522.1840, consistent with $\mathrm{C}_{25} \mathrm{H}_{31} \mathrm{Cl}_{2} \mathrm{FN}_{5} \mathrm{O}_{2}$ (calculated $\mathrm{m} / \mathrm{z}$ $522.1833, \mathrm{mo}=20.0$ ). A doubly charged $[\mathrm{M}+2 \mathrm{H}]^{2+}$ ion is also observed at $\mathrm{m} / \mathrm{z} 261.6$. The chemical formulae of fragments observed in the MS and MS/MS data were again verified with $\mathrm{SF}$ and SF3D (data not shown). The formula is $\mathrm{C}_{4} \mathrm{H}_{8} \mathrm{O}$ higher than that of crizotinib. The presence of a $\mathrm{m} / \mathrm{z} 156.1387$ fragment $\left(\mathrm{C}_{9} \mathrm{H}_{18} \mathrm{NO}\right.$, calculated $\mathrm{m} / z$ 156.1383) locates the extra $\mathrm{C}_{4} \mathrm{H}_{8} \mathrm{O}$, once again, on the piperidine ring nitrogen (compare fragments $\mathrm{m} / \mathrm{z} 84$ and 140 in the previous discussion). The structure of Impurity B $(\mathrm{m} / \mathrm{z} 522)$ is assigned as the N-hydroxybutyl analogue, 3 , after consideration of the synthetic route. 


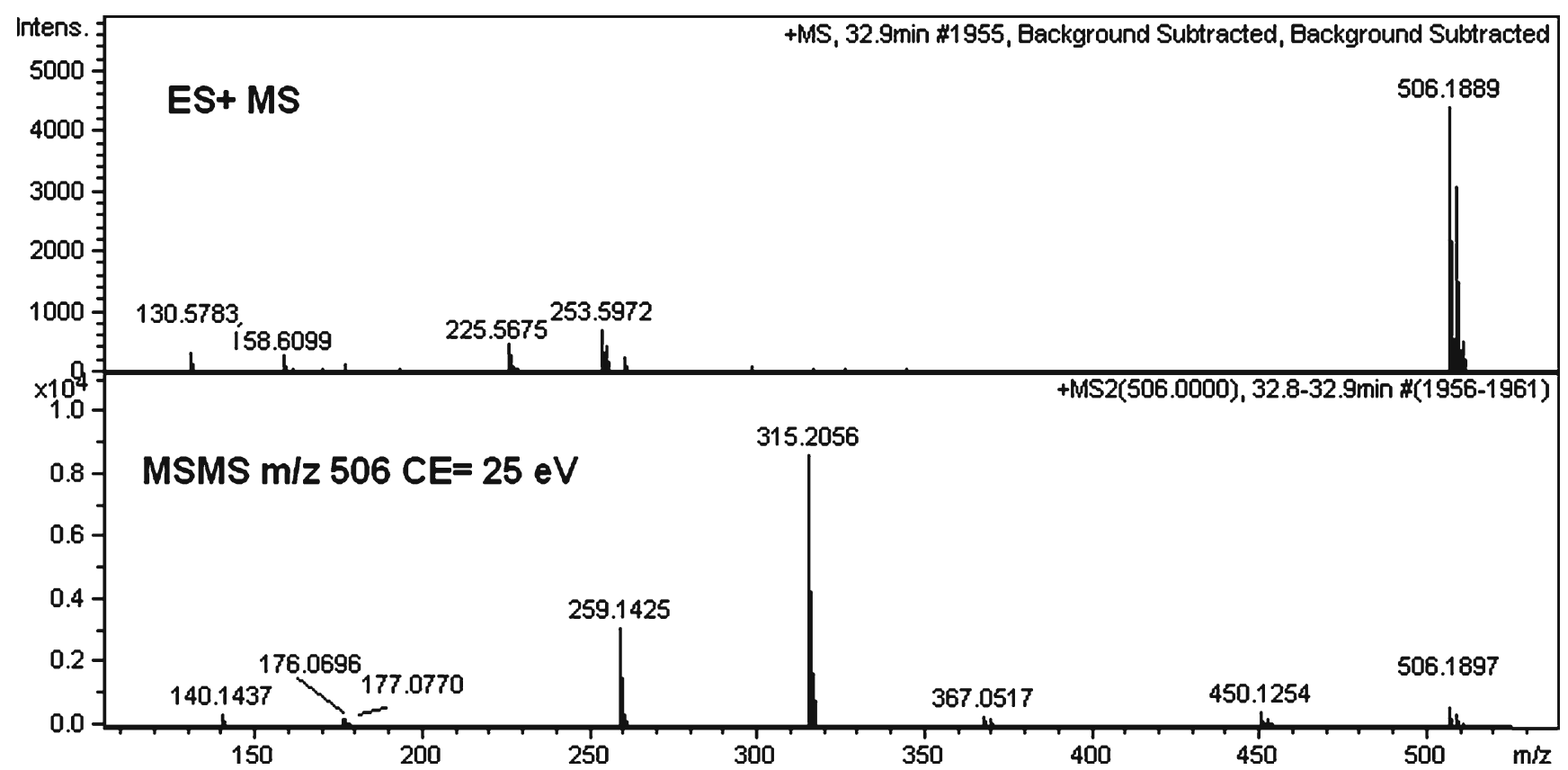

Figure 2. ES+ MS and MS/MS data for Impurity A ( $m / z$ 506). Top: Full Scan MS. Bottom: MS/MS product ion data for $m / z 506$ (collision energy $25 \mathrm{eV}$ )

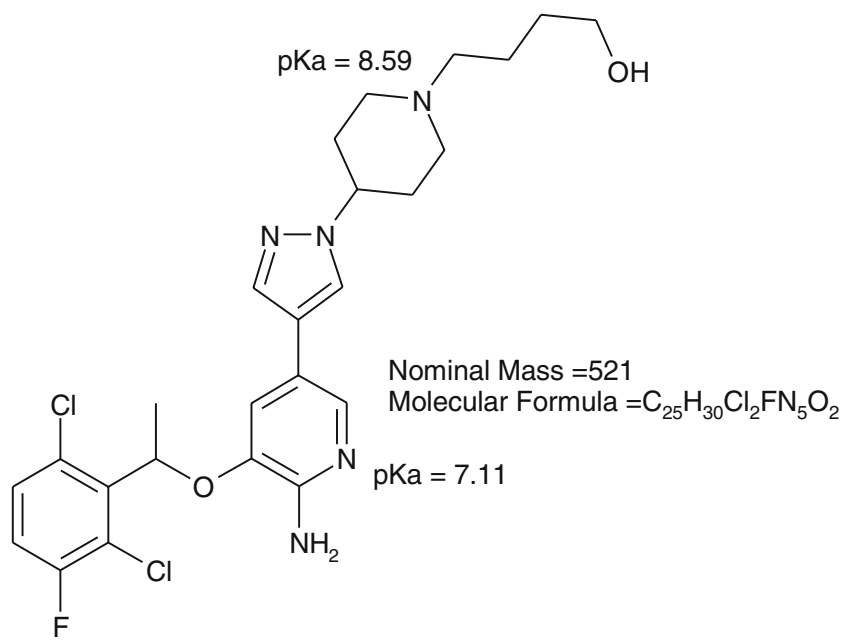

3
The piperidine nitrogen is predicted to be slightly less basic than in crizotinib but is still the preferred site of protonation, based on solution thermodynamics. The full scan MS spectrum of this impurity and that of crizotinib are similar, suggesting that the two compounds protonate, and hence fragment, in a similar way. However, the product ion MS/MS data for $m / z 522$ show greater similarity to data for Impurity A ( $m / z 506)$, with a major odd-electron fragment of $m / z 331.2006\left(\mathrm{C}_{17} \mathrm{H}_{25} \mathrm{~N}_{5} \mathrm{O}_{2}\right.$, calculated $m / z 331.2003 \mathrm{m \sigma}=$ 11.7), equivalent to the $m / z 315$ fragment observed in the product ion MS/MS spectrum of Impurity A $(\mathrm{m} / \mathrm{z} 506)$. This again suggests that the first site of protonation is the thermodynamically less favored pyridine nitrogen and that this is determined by kinetic factors due to steric hindrance of the more favored site. The proclivity for double protonation, as evidenced by the full scan MS spectrum, is a clear indication that the piperidine nitrogen is less sterically

Table 1. Impurity A ( $m / z 506)$ : MS and MS/MS data and formula assignments

\begin{tabular}{|c|c|c|c|c|c|c|}
\hline MS/ MS/MS & Observed $\mathrm{m} / \mathrm{z}$ & Assigned formula & Calculated $\mathrm{m} / \mathrm{z}$ & $\mathrm{m} \sigma$ & Error (mDa) & Odd/even electron \\
\hline \multirow[t]{5}{*}{ MS } & $506.1889^{+}$ & $\mathrm{C}_{25} \mathrm{H}_{31} \mathrm{Cl}_{2} \mathrm{FN}_{5} \mathrm{O}$ & 506.1884 & 13.8 & 0.5 & Even \\
\hline & $253.5972^{2+}$ & $\mathrm{C}_{25} \mathrm{H}_{32} \mathrm{Cl}_{2} \mathrm{FN}_{5} \mathrm{O}$ & 253.5978 & 70.4 & 0.6 & Even \\
\hline & $225.5675^{2+}$ & $\mathrm{C}_{21} \mathrm{H}_{24} \mathrm{Cl}_{2} \mathrm{FN}_{5} \mathrm{O}$ & 225.5665 & 46.8 & 1.0 & Even \\
\hline & $158.6099^{2+}$ & $\mathrm{C}_{17} \mathrm{H}_{27} \mathrm{~N}_{5} \mathrm{O}$ & 158.6102 & 30.8 & 0.3 & Even \\
\hline & $130.5783^{2+}$ & $\mathrm{C}_{13} \mathrm{H}_{19} \mathrm{~N}_{5} \mathrm{O}$ & 130.5789 & 6.9 & 0.6 & Even \\
\hline \multirow[t]{7}{*}{ MS/MS } & $450.1254^{+}$ & $\mathrm{C}_{21} \mathrm{H}_{23} \mathrm{Cl}_{2} \mathrm{FN}_{5} \mathrm{O}$ & 450.1258 & 64.6 & 0.4 & Even \\
\hline & $367.0517^{+}$ & $\mathrm{C}_{16} \mathrm{H}_{14} \mathrm{Cl}_{2} \mathrm{FN}_{4} \mathrm{O}$ & 367.0523 & 75.2 & 0.6 & Even \\
\hline & $315.2056^{+}$ & $\mathrm{C}_{17} \mathrm{H}_{25} \mathrm{~N}_{5} \mathrm{O}$ & 315.2054 & 6.9 & 0.2 & Odd \\
\hline & $259.1425^{+}$ & $\mathrm{C}_{13} \mathrm{H}_{17} \mathrm{~N}_{5} \mathrm{O}$ & 259.1428 & 31.3 & 0.3 & Odd \\
\hline & $177.0770^{+}$ & $\mathrm{C}_{8} \mathrm{H}_{9} \mathrm{~N}_{4} \mathrm{O}$ & 177.0771 & 58.5 & 0.1 & Even \\
\hline & $176.0696^{+}$ & $\mathrm{C}_{8} \mathrm{H}_{8} \mathrm{~N}_{4} \mathrm{O}$ & 176.0693 & 36.6 & 0.3 & Odd \\
\hline & $140.1437^{+}$ & $\mathrm{C}_{9} \mathrm{H}_{18} \mathrm{~N}$ & 140.1434 & 17.8 & 0.3 & Even \\
\hline
\end{tabular}




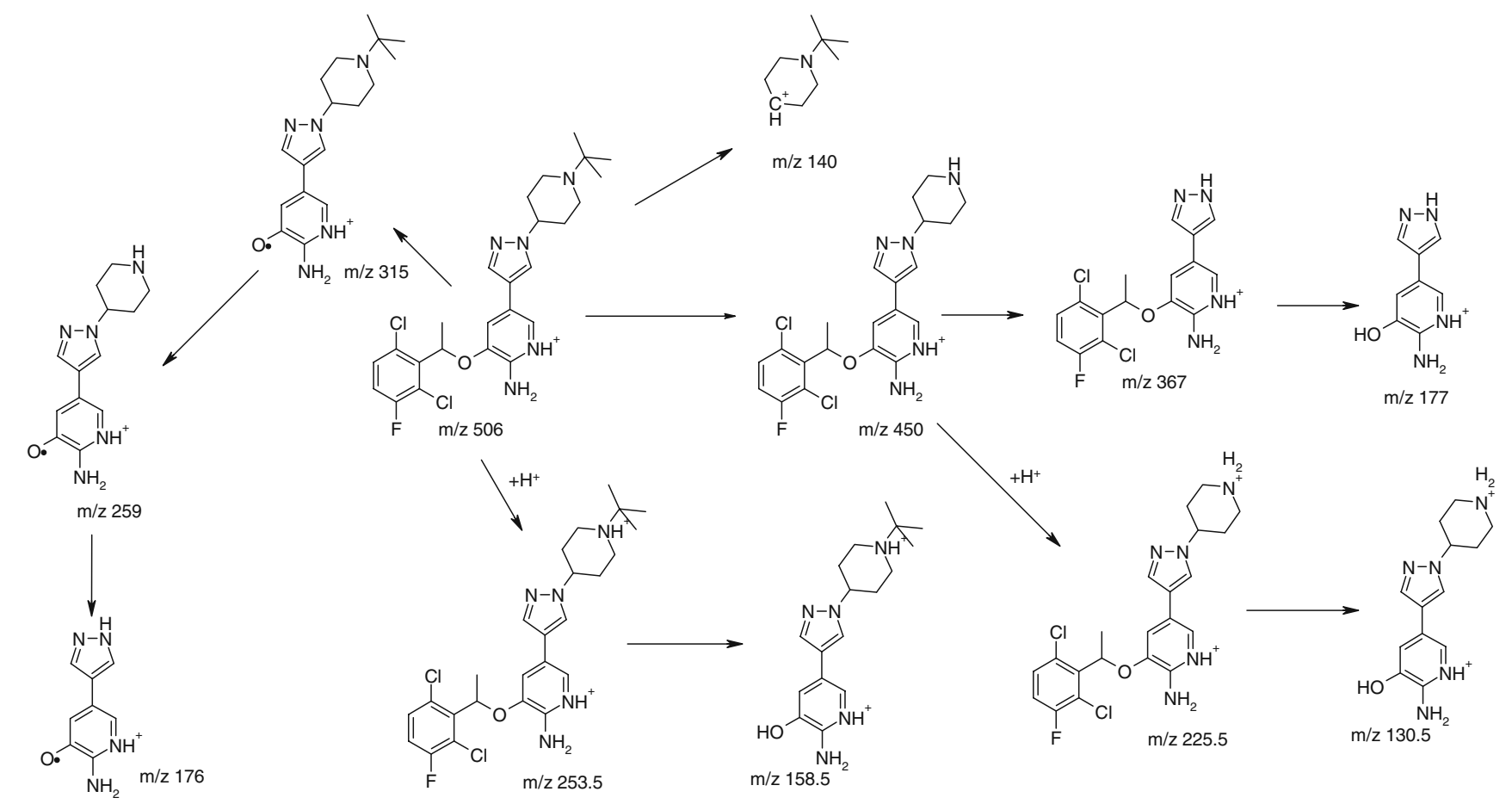

Scheme 2. Impurity A ( $m / z 506)-M S$ and CID MS/MS fragmentation

hindered in the hydroxybutyl impurity (Impurity B, 3) than it is in the t-butyl impurity (Impurity A, 2), providing further evidence that these assignments are correct. The fragmentation of Impurity B $(m / z 522)$ is detailed in Scheme 3, which also shows the assignment of the fragment $\mathrm{m} / \mathrm{z} 272.1511$ $\left(\mathrm{C}_{14} \mathrm{H}_{18} \mathrm{~N}_{5} \mathrm{O}\right.$, calculated $\left.\mathrm{m} / \mathrm{z} 272.1506 \mathrm{mo}=15.8\right)$, providing additional evidence of this structure assignment.
Gas Phase Proton Affinities-an Alternative Explanation?

The mechanism of ion formation during electrospray has been discussed in detail elsewhere [1, 5, and references therein]. It has been postulated that gas phase ions are produced either via complete evaporation of the droplet [23]

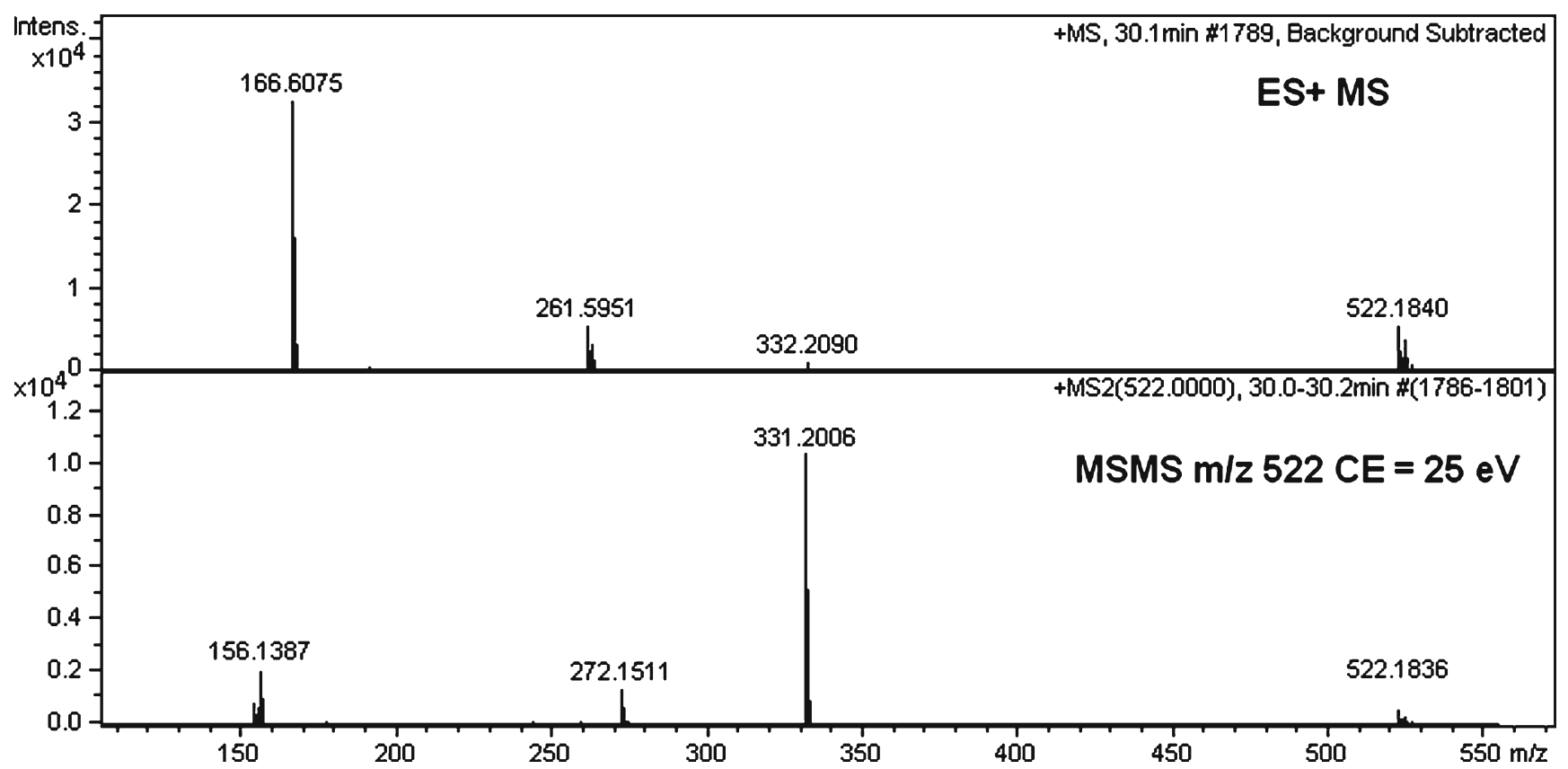

Figure 3. ES+ MS and MS/MS data for Impurity B ( $m / z$ 522). Top: Full Scan MS. Bottom: MS/MS product ion data for $m / z 522$ (collision energy $25 \mathrm{eV}$ ) 
<smiles>Nc1[nH+]cc(-c2cnn(C3CCN(CCCCO)CC3)c2)cc1Cl</smiles>

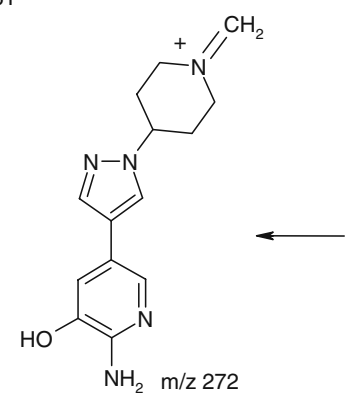<smiles>OCCCCN1CCCCC1</smiles>

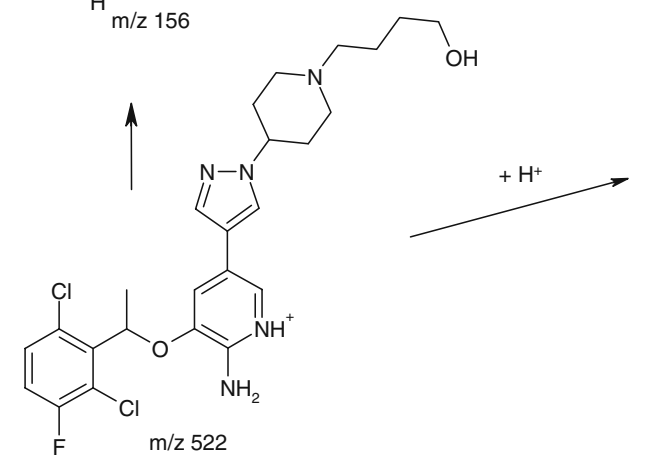

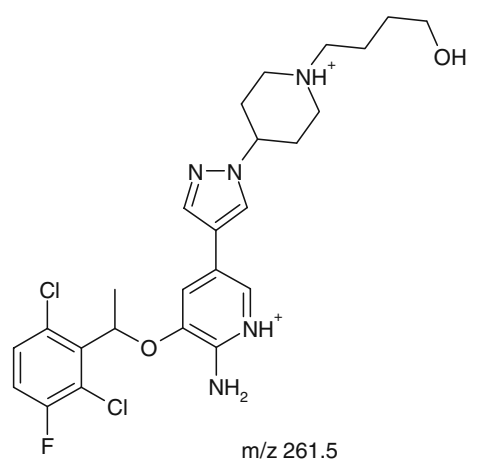

$\downarrow$

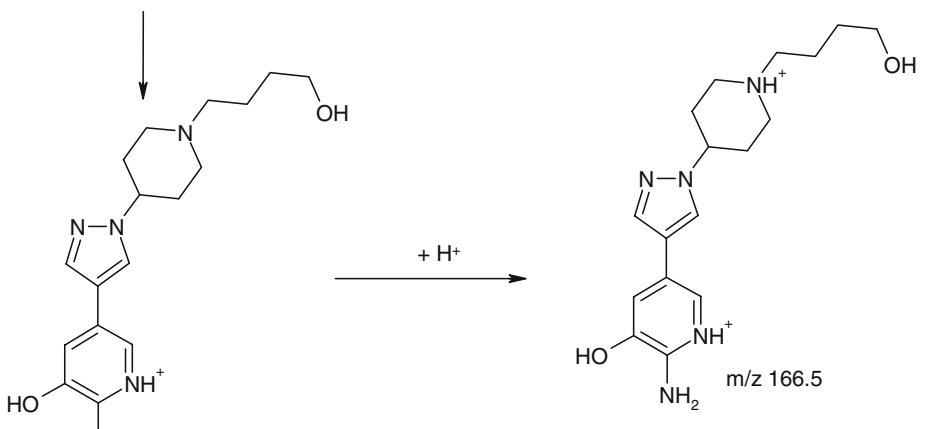

Scheme 3. Impurity B ( $\mathrm{m} / \mathrm{z} 522)-\mathrm{MS}$ and CID MS/MS fragmentation

or that excess charge on the droplet surface causes ions to evaporate into the gas phase [24]. It is not fully understood whether the solution phase $\mathrm{p} K a$ values or the gas phase proton affinity (PA) values determine the thermodynamically most favored site of protonation. Ehrmann et al. [5] point out that these two values can be very different and also illustrate the difficulty of determining the true PA of the analyte, which is likely to be solvated in the gas phase, compared with published values of the bare analyte. They conclude, after examination of the protonation behavior of a large number of a diverse series of protonatable analytes, that solution chemistry is the most important parameter for determining electrospray response and that electrospray response was low for analytes that were poor bases in solution even if they had very high gas phase basicity.

Nevertheless, a discussion of PAs is highly relevant in relation to the site of protonation in crizotinib and related structures. Koné et al. [6] have shown that the thermodynamic properties of nicotine (Figure 4), which contains a pyridine ring nitrogen (sp2) and a N-methyl substituted pyrollidine ring nitrogen (sp3) differ greatly in solution and gas phase. In solution, the sp3 nitrogen is more basic by $13.3 \mathrm{~kJ} \mathrm{~mol}^{-1}$, resulting in $>98 \%$ protonation of the $\mathrm{sp} 3$ pyrollidine nitrogen. Similar solution data are obtained for nornicotine (Figure 4), which differs in structure with the loss of the methyl group, resulting in the pyrollidine ring nitrogen becoming a secondary amine. However, in the gas phase, the pyridine nitrogen (sp2) and pyrollidine nitrogen (sp3) have very similar PAs in nicotine, and in nornicotine, the $\mathrm{sp} 2$ nitrogen has a much higher PA than the sp3 nitrogen by $20.8 \mathrm{~kJ} \mathrm{~mol}^{-1}$. By analogy, it might be expected that anabasine and $\mathrm{N}$-methylanabasine (Figure 4), which contain a pyridine nitrogen (sp2) and a piperidine nitrogen (sp3) and, thus, are closer analogues to crizotinib and its impurities, would behave similarly. Indeed, the same authors [6], whilst not quoting solution data for anabasine and N-methylanabasine, calculate that in the gas<smiles>CN1CCCC1c1cccnc1</smiles>

Nicotine<smiles>c1cncc(C2CCCN2)c1</smiles>

Nornicotine<smiles>CN1CCCCC1c1cccnc1</smiles>

N-Methylanabasine<smiles>c1cncc(C2CCCCN2)c1</smiles>

Anabasine

Figure 4. Structures of nicotine, nornicotine, $N$-methylanabasine, and anabasine 


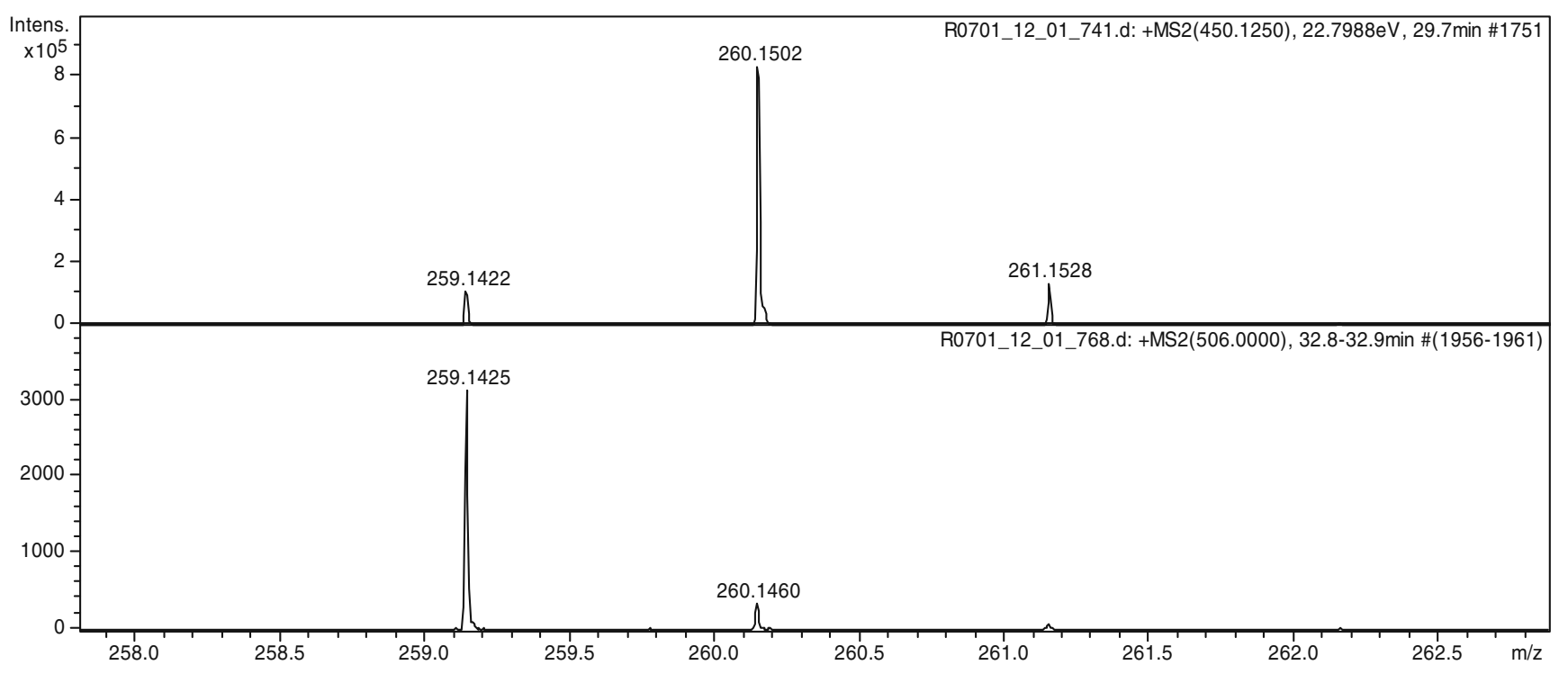

Figure 5. MS/MS data for crizotinib (top) and Impurity A (bottom), expanded around $\mathrm{m} / \mathrm{z} 260$. (Note that the calculated $\mathrm{m} / \mathrm{z}$ for the ${ }^{13} \mathrm{C}$ isotope ion of odd-electron $\mathrm{m} / \mathrm{z} 259$ is 260.1460)

phase, protonation of the sp2 nitrogen is favored in anabasine by $14.0 \mathrm{~kJ} \mathrm{~mol}^{-1}$, whereas the PAs of the two nitrogens in N-methylanabasine are, again, very similar.

If the site of protonation in crizotinib and related structures were determined thermodynamically by gas phase PA rather than solution $\mathrm{pKa}$ values, crizotinib would be expected to protonate almost exclusively on the pyridine nitrogen (sp2), i.e. not as shown in Scheme 1, and the two N-substituted impurities (Impurities A and B) would be expected to protonate at one or other of the two sites with approximately equal favor. We believe that this does not correlate with the experimental observations, which strongly support the notion that the two $\mathrm{N}$-substituted structures protonate on a single site (for the monoprotonated species), and that site is different from the site of protonation of the monoprotonated species in crizotinib itself. Figure 5 shows the expanded region of the MS/MS spectra for crizotinib and Impurity A. The crizotinib data show an intense even-electron $\mathrm{m} / \mathrm{z} 260$ ion, proposed to originate from the piperidine protonated molecular ion, as discussed earlier, as well as a low-level odd-electron $\mathrm{m} / \mathrm{z} 259$ ion, which indicates a small contribution to the fragmentation from the pyridine protonated molecular ion. The Impurity A data show an intense odd-electron $\mathrm{m} / \mathrm{z} 259$ ion with virtually no contribution of the even-electron $\mathrm{m} / \mathrm{z} 260$ ion. This suggests that protonation occurs almost exclusively on one site, proposed to be the pyridine nitrogen, which is not consistent with gas phase PA predictions.

\section{Conclusion}

Kinetic control of protonation in electrospray ionization is demonstrated by reference to MS and MS/MS spectra of crizotinib and two related impurities. In crizotinib itself, the secondary amine (the piperidine nitrogen, predicted $\mathrm{p} K a$ 9.81) is the preferred site of protonation, as expected from thermodynamic considerations, although the pyridine nitrogen (predicted $\mathrm{pKa}$ 7.11) can also be protonated to give doubly charged ions. The N-t-butyl tertiary amine impurity (Impurity A) protonates preferentially on the pyridine nitrogen despite the tertiary amine nitrogen being by far the most basic site on the molecule (predicted $\mathrm{pKa}$ 10.02). Limited additional protonation of the piperidine nitrogen occurs to give doubly charged ions. The N-hydroxybutyl tertiary amine impurity (Impurity B) also ionizes preferentially on the less basic pyridine nitrogen, although a significant amount of additional protonation of the piperidine nitrogen ( $\mathrm{pKa} 8.59)$ is observed in the full scan MS spectrum because of a lower degree of steric hindrance of the piperidine nitrogen compared to Impurity A. The ions observed in the MS/MS spectrum of Impurity B suggest that fragmentation is predominantly from the pyridine nitrogen protonated species.

These observations are surprising if the electrospray spectrum is a reflection of the state of protonation of the molecule in solution, because it would be anticipated that equilibrium would be established to produce the thermodynamically most stable protonated state in the time scale of HPLC. This strongly supports the proposal that mechanisms other than in-solution ionization may be important in ion formation by the electrospray process $[11,12]$. Indeed, the $\mathrm{pH}$ of the liquid phase becomes a meaningless concept by the end of the electrospray process as a protonated molecule emerges from the final, highly charged, droplet into the gas phase [13]. However, the data do not support the proposition that the site of protonation is determined solely by the thermodynamics of gas phase PAs. These observations, together with literature precedence [2, 3, 9, 10] of steric hindrance directing the protonation site in chemical ionization, suggest that a greater consideration of steric hindrance should be made in interpretation of electrospray data and in discussions of the electrospray mechanism. 


\section{References}

1. Kebarle, P., Tang, L.: From ions in solution to ions in the gas phase. Anal. Chem. 65(22), 972A-986A (1993)

2. Vais, V., Etinger, A., Mandelbaum, A.: Intramolecular proton transfers in stereoisomeric gas-phase ions and the kinetic nature of the protonation process upon chemical ionization. J. Mass Spectrom. 34, 755-760 (1999)

3. Vais, V., Etinger, A., Mandelbaum, A.: Steric hindrance and the kinetic nature of the protonation process in 4-amino-1-methoxycyclohexanes upon chemical ionization. Eur. Mass Spectrom. 5, 449-454 (1999)

4. Tu, Y.-P.: Dissociative protonation sites: reactive centers in protonated molecules leading to fragmentation in mass spectrometry. J. Org. Chem. 71, 5482-5488 (2006)

5. Ehrmann, B.M., Henriksen, T., Cech, N.B.: Relative importance of basicity in the gas phase and in solution for determining selectivity in electrospray ionization mass spectrometry. J. Am. Soc. Mass Spectrom. 19, 719-728 (2008)

6. Koné, M., Illien, B., Laurence, C., Gal, J.-F., Maria, P.-C.: Are nicotinoids protonated on the pyridine or the amino nitrogen in the gas phase? J. Phys. Org. Chem. 19, 104-114 (2006)

7. Wright, P., Alex, A., Nyaruwata, T., Parsons, T., Pullen, F.: Using density functional theory to rationalise the mass spectral fragmentation of maraviroc and its metabolites. Rapid Commun. Mass Spectrom. 24 , 1025-1031 (2010)

8. Tian, Z., Kass, S.R.: Gas-phase versus liquid-phase structures by electrospray ionization mass spectrometry. Angew. Chem. Int. Ed. 48, 1321-1323 (2009)

9. Weisz, A., Cojocaru, M., Mandelbaum, A. Site specific gas-phase protonation of 2-t-butylmaleates and 2-t-butylsuccinates upon chemical ionization: stereochemical effects and kinetic control. J. Chem.Soc.; Chem. Commun. 331-332 (1989)

10. Ari, J.B., Navon, I., Mandelbaum, A.: The effect of steric hindrance on the relative rates of anchimerically assisted alcohol eliminations from $\mathrm{MH}^{+}$ions of 2-substituted 1,4-dialkoxybutanes upon CI and CID: experiment and theory. Int. J. Mass Spectrom. 249/250, 433-445 (2006)

11. Jeanville, P.M., Estapé, E.S., de Jeanville, I.T.-N.: The effect of liquid chromatography eluents and additives on the positive ion responses of cocaine, benzoylecgonine, and ecgonine methyl ester using electrospray ionization. Int. J. Mass Spectrom. 227, 247-258 (2003)

12. Delatour, C., Leclerq, L.: Positive electrospray liquid chromatography/ mass spectrometry using high-pH gradients: a way to combine selectivity and sensitivity for a large variety of drugs. Rapid Commun Mass Spectrom. 19, 1359-1362 (2005)

13. Peng, L., Farkas, T.: Analysis of basic compounds by reversed phase liquid chromatography-electrospray mass spectrometry in high-pH mobile phases. J. Chromatogr. A 1179, 131-144 (2008)

14. Kamel, A.M., Brown, P.R., Munson, B.: Effects of mobile-phase additives, solution $\mathrm{pH}$, ionization constant, and analyte concentration on the sensitivities and electrospray ionization mass spectra of nucleoside antiviral agents. Anal. Chem. 71, 5481-5492 (1999)

15. Ojanperä, S., Pelander, A., Pelzing, M., Krebs, I., Vuori, E., Ojanperä, I.: Isotopic pattern and accurate mass determination in urine drug screening by liquid chromatography/time-of-flight mass spectrometry. Rapid Commun. Mass Spectrom. 20, 1161-1167 (2006)

16. Bristow, T., Constantine, J., Harrison, M., Cavoit, F.: Performance optimisation of a new generation orthogonal-acceleration quadrupoletime-of-flight mass spectrometer. Rapid Commun. Mass Spectrom. 22, 1213-1222 (2008)

17. Dinelli, G., Carretero, A.S., Di Silvestro, R., Marotti, I., Fu, S., Benedettelli, S., Ghiselli, L., Gutierrez, A.F.: Determination of phenolic compounds in modern and old varieties of durum wheat using liquid chromatography coupled with time-of-flight mass spectrometry. $J$. Chromatogr. A 1216, 7229-7240 (2009)

18. Peters, R.J.B., Bolck, Y.J.C., Rutgers, P., Stolker, A.A.M., Nielen, M. W.F.: Multi-residue screening of veterinary drugs in egg, fish and meat using high-resolution liquid chromatography accurate mass time-offlight mass spectrometry. J. Chromatogr. A 1216, 8206-8216 (2009)

19. Pelander, A., Tyrkkö, E., Ojanperä, I.: In silico methods for predicting metabolism and mass fragmentation applied to quetiapine in liquid chromatography/time-of-flight mass spectrometry urine drug screening. Rapid Commun. Mass Spectrom. 23, 506-514 (2009)

20. Stacey, C., Goetz, S., Baessmann, C., Seymour, C.: Certainty in small molecule identification by applying smart formula $3 \mathrm{D}$ on a UHR-TOF mass spectrometer. Chem NZ 72(3), 118-119 (2008)

21. Tyrkkö, E., Pelander, A., Ojanperä, I.: Differentiation of structural isomers in a target drug database by LC/Q-TOFMS using fragmentation prediction. Drug Test. Anal. 2, 259-270 (2010)

22. Advanced Chemical Development, $\mathrm{pKa}$ Database Software, www. acdlabs.com.

23. Dole, M., Mack, L.L., Hines, R.L., Mobley, R.C., Ferguson, L.D., Alice, M.B.: Molecular beams of macroions. J. Chem. Phys. 49, 22402249 (1968)

24. Iribarne, J.V., Thomson, B.A.: On the evaporation of charged ions from small droplets. J. Chem. Phys. 64, 2287-2294 (1976) 